\title{
Optimierung der dentalen Biofilmkontrolle
}

Listerine ist im Rahmen der täglichen 3-Fach-Prophylaxe eine optimale Ergänzung zur mechanischen Zahnreinigung mit Zahnbürste und Interdentalpflege. Nachweislich erhöht die ergänzende Verwendung von Listerine die Plaquereduktion um 52\% im Vergleich zu Zähneputzen und Zahnseide allein. Die Wirkung von den Mundspülungen beruht auf den 4 enthaltenen lipophilen ätherischen Ölen Eukalyptol, Thymol, Menthol und Methylsalizylat. Sie bekämpfen nicht nur ein breites Spektrum an planktonischen Bakterien, sondern dringen darüber hinaus tief in den dentalen Biofilm ein. Gleichzeitig lassen sich in der Langzeitanwendung von Listerine weder negative Auswirkungen auf das natürliche Gleichgewicht der Mundflora, noch Zahn- oder Zahnfleischverfärbungen feststellen. Die Initiative 3-Fach-Prophylaxe von Listerine gibt Dentalexperten Informationen und Services rund um die Integration von Mundspülungen in die tägliche Mundhygiene an die Hand und unterstützt sie so bei der Prophylaxe-Beratung der Patienten. Zentrales Element der Initiative 3-Fach-Prophylaxe ist die Seite www.listerineprofessional.de/initiative-3-fach-prophylaxe

Nach einer Pressemitteilung der Johnson \& Johnson GmbH, Neuss

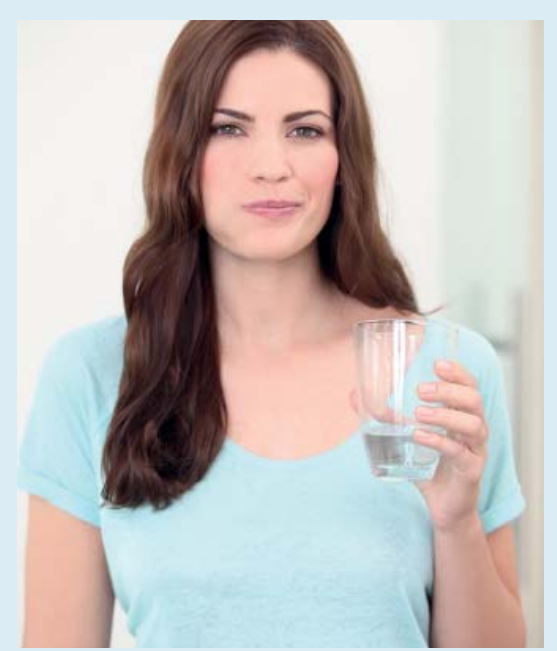

